Article

\title{
Probing Internalization Effects and Biocompatibility of Ultrasmall Zirconium Metal-Organic Frameworks UiO-66 NP in U251 Glioblastoma Cancer Cells
}

\author{
Cataldo Arcuri ${ }^{1, *}$, Lorenzo Monarca ${ }^{2}$, Francesco Ragonese ${ }^{2}$, Carmen Mecca ${ }^{1}$, Stefano Bruscoli ${ }^{3}$, \\ Stefano Giovagnoli ${ }^{4}$, Rosario Donato ${ }^{1}$, Oxana Bereshchenko ${ }^{3} \mathbb{D}$, Bernard Fioretti ${ }^{2}$ \\ and Ferdinando Costantino ${ }^{2, *}$ \\ 1 Department of Experimental Medicine, Perugia Medical School, University of Perugia, Piazza Lucio Severi 1, \\ 06132 Perugia, Italy; carmen.mecca@unipg.it (C.M.); rosario.donato@unipg.it (R.D.) \\ 2 Department of Chemistry, Biology and Biotechnologies, University of Perugia, Via Elce di Sotto 8, \\ 06123 Perugia, Italy; lorenzomonarca.92@gmail.com (L.M.); francescoragonese85@gmail.com (F.R.); \\ bernard.fioretti@unipg.it (B.F.) \\ 3 Department of Medicine, Perugia Medical School, University of Perugia, Piazza Lucio Severi 1, \\ 06132 Perugia, Italy; stefano.bruscoli@unipg.it (S.B.); oxana.bereshchenko@unipg.it (O.B.) \\ 4 Department of Pharmaceutical Sciences, University of Perugia, Via A. Fabretti 48, 06123, Perugia, Italy; \\ stefano.giovagnoli@unipg.it \\ * Correspondence: cataldo.arcuri@unipg.it (C.A.); ferdinando.costantino@unipg.it (F.C.); \\ Tel.: +39-0750-585-5563 (F.C.)
}

Received: 28 September 2018; Accepted: 19 October 2018; Published: 23 October 2018

\begin{abstract}
The synthesis of ultrasmall UiO-66 nanoparticles (NPs) with an average size of $25 \mathrm{~nm}$, determined by X-ray powder diffraction and electron microscopies analysis, is reported. The NPs were stabilized in water by dialyzing the NP from the DMF used for the synthesis. DLS measurements confirmed the presence of particles of $100 \mathrm{~nm}$, which are spherical aggregates of smaller particles of 20-30 nm size. The NP have a BET surface area of $700 \mathrm{~m}^{2} / \mathrm{g}$ with an external surface area of $300 \mathrm{~m}^{2} / \mathrm{g}$. UiO-66_N (UiO-66 nanoparticles) were loaded with acridine orange as fluorescent probe. UV-vis spectroscopy analysis revealed no acridine loss after $48 \mathrm{~h}$ of agitation in simulated body fluid. The biocompatibility of UiO-66_N was evaluated in human glioblastoma (GBM) cell line U251, the most malignant (IV grade of WHO classification) among brain tumors. In U251 cells, UiO-66_N are inert since they do not alter the cell cycle, the viability, migration properties, and the expression of kinases involved in cancer cell growth. The internalization process was evident after a few hours of incubation. After 24 h, UiO-66_N@Acr (UiO-66_N loaded with acridine orange) were detectable around the nuclei of the cells. These data suggest that small UiO-66 are biocompatible NP and could represent a potential carrier for drug delivery in glioblastoma therapies.
\end{abstract}

Keywords: UiO-66; nanoparticles; glioblastoma; biocompatibility; drug delivery

\section{Introduction}

In the recent past, nanomedicine has become an attractive approach for targeted drug delivery and for new therapeutic strategies able to overcome the traditional limitations due to toxicity, healthy tissue damage, or other undesired side effects of direct drug administration [1-3]. The synthesis and application of nano-objects to be employed for therapeutic, pharmacological and diagnostic purposes has been rapidly growing [4,5]. Metallic nanoparticles (NPs), (i.e., plasmonic gold nanoclusters, silver $\mathrm{NP}$, ferrite or magnetite superparamagnetic NP) of very small size are currently used as theranostic agents in living cells for a large number of diseases [6-8]. Nanomaterials are able to offer an efficient 
drug delivery by means of cellular internalization after encapsulation or surface attachment of the drugs. The use of nanocarriers such as lyposomes and dendrimers to be used in physiological conditions for drug delivery is also of great interest [9]. Among the mentioned compounds commonly used for these purposes, there is a class of materials called metal-organic frameworks (MOF) which has already been used for several application as drug delivery carriers and for imaging in living cells [10-13]. MOF are inorganic-organic hybrid compounds with porous crystalline structure and they are constituted of polynuclear metal clusters (also called nodes) linked each other by organic ligands such as carboxylate, phosphonates, heterocycles, and so on. The regular arrangement of nodes and ligands designs porous cages, normally filled by solvent molecules that make these materials suitable for transportation of bioactive molecules to be released in living cells [14-16]. Therapeutic agents and drugs_-such as antibacterial and antiviral [17], as well as anticancer drugs like cisplatin [18] - have been successfully included in MOF NP and tested in living cells. In light of their low cytotoxicity, $\mathrm{Zn}$ and Fe based MOF are still the most employed. However, $\mathrm{Zr}$ based MOF are today considered the benchmark MOF materials in many fields [19]. UiO-66, which structure was first published by Lillerud et al. in 2008, has formula $\left(\left(\mathrm{Zr}_{6} \mathrm{O}_{4}(\mathrm{OH})_{4}\left(\mathrm{O}_{2} \mathrm{C}-\mathrm{C}_{6} \mathrm{H}_{4}-\mathrm{CO}_{2}\right)_{6}\right)\right.$ and it is composed of hexa-zirconium(IV) oxo hydroxyl clusters, which are 12-connected by means of linear terephthalate linkers to form a cubic network with small tetrahedral and large octahedral cavities connected through narrow triangular pore windows about $1 \mathrm{~nm}$ wide [20]. It is well known that this structure is highly defective and the internal terephtalate linker can be replaced by monocarboxylic groups like acetate, benzoate, and formiate, thus increasing the internal pore volume [21]. Depending on the crystallinity degree the internal surface area can vary from 900 to $1300 \mathrm{~m}^{2} / \mathrm{g}$ and the pore volume from 0.35 to $0.5 \mathrm{~cm}^{3} / \mathrm{g}$. Generally, UiO- 66 crystals with 200 to $500 \mathrm{~nm}$ size can be obtained by conventional hydrothermal synthesis. However, crystals of ultrasmall size of $20-30 \mathrm{~nm}$ can be fabricated by properly changing synthetic conditions (amount of water, crystallinity modulator, and aging of the $\mathrm{Zr}$ (IV) solutions) [22,23]. Despite the ultrasmall size, the structure of UiO-66 is preserved at the expenses of a reduction of the internal surface area $\left(400 \mathrm{~m}^{2} / \mathrm{g}\right.$, pore volume $\left.0.16 \mathrm{~cm}^{3} / \mathrm{g}\right)$. On the other hand, the small size of the NP strongly increases the external surface area of about 5 to 10 times with respect to large crystals (up to $400 \mathrm{~m}^{2} / \mathrm{g}$ for $15 \mathrm{~nm}$ average size crystals) [23]. The use of such a small particles could be of potential interest for their potential capacity to easily pass the blood-brain barrier. Recently, surface modified UiO-66 nanocrystals have been used as luminescent sensors for cysteine and GHS detection [24] to unveil the endocytosis mechanism in He-La cells [25], for $\mathrm{pH}$ responsive drug delivery after surface PEGylation [26], as anticancer drug carriers after modification with $\varepsilon$-polycaprolactone [17], folic acid, and fluorescent markers (BODYPI) for enhanced cellular uptake [27]. UiO-66 NP have been recently employed after mechanical amorphization for studying the release of fluorescent dye calcein and $\alpha$-cyano-4-hydroxycinnamic acid $(\alpha-\mathrm{CHC})[28,29]$ and also for miRNA detection [30]. Herein, we report the synthesis of ultrasmall UiO-66_N, their stabilization in water dispersion through dialysis, the loading with fluorescent acridine orange and the study of internalization and biocompatibility on U251 Glioblastoma cells line. Glioblastoma multiforme (GBM) is the most malignant (IV grade of WHO classification) and the most frequent among brain tumors of neuroepithelial origin [31]. The incidence in the United States is 2.96 cases $/ 1,000,000$ population/year with a higher peak in males older than 40 years of age [32]. The therapeutic approach to this tumor is complicated primarily by the proximity to the brain parenchyma, but also by the high infiltration capacity and low radio-sensitivity. Standard treatments include surgery, whenever possible, chemotherapy and radiotherapy, according to the Stupp's protocol [33]. Nonetheless, the median survival remains 6 months after surgery alone, while surgery plus radiotherapy extends median survival to 12 months [34]. Moreover, recent experimental evidences have shown that, like other tumors, also GBM harbor a subpopulation of cancer stem cells, namely glioblastoma stem cells (GSCs) that are quiescent and thus evade radio and chemotherapy, causing tumor relapse [35]. To date, numerous genetic alterations of oncogene or tumor suppressor genes have been identified in GBM, including EGFR, PDGFRA, PIK3C2B, p16INK4a/p14ARF, PTEN, and RB1 [36], considering that many 
of these mutations result in an uncontrolled activation of tyrosine kinase receptors (TKR) and their downstream pathways, many efforts have been made to inhibit these deregulated pathways without significant result. The MOF incorporation in U251 cells was evaluated by flow cytometry after loading of the NP with acridine orange (UiO-66_N@Acr). Cytotoxicity studies, cell cycle evaluation, migration tests were also performed. Moreover, two major signaling pathways were also considered: ERK1/2 and PTEN/PI3K/Akt. The results obtained show that U251 cells internalize UiO-66_N without altering their physiology. These observations suggest that UiO-66_N may represent suitable nanocarriers to target drugs and/or active molecules to glioblastoma cells.

\section{Materials and Methods}

\subsection{Chemicals}

$\mathrm{ZrCl}_{4}$, acetic acid (99.5\%), terephtalic acid, N,N-dimethylformamide were purchased from Sigma-Aldrich ${ }^{\circledR}$ (St. Louis, MO, USA). The biological reagents are described along the experimental section.

\subsection{Synthesis of Nanometric UiO-66_N (Average Crystal Size $25 \mathrm{~nm}$ )}

UiO-66_N was prepared by dissolving $0.35 \mathrm{~g}$ of $\mathrm{ZrCl}_{4}(1.5 \mathrm{mmol})$ in $15 \mathrm{~mL}$ of DMF in a $50 \mathrm{~mL}$ Teflon vial. Then $0.635 \mathrm{~mL}$ of water $(0.035 \mathrm{mmol})$ were added to the mixture. $1.4 \mathrm{~mL}(0.024 \mathrm{mmol})$ of acetic acid was added. The mixture was aged for 2 days at room temperature (RT). After that, $5 \mathrm{~mL}$ of $0.3 \mathrm{M} 1,4$ benzenedicarboxylic acid (BDC) solution in DMF was then added to the mixture. The Teflon vial was put in an oven at $120^{\circ} \mathrm{C}$ for $24 \mathrm{~h}$. After this time, a gel was recovered, washed twice with acetone and once with water. Then the solid was dried at $60^{\circ} \mathrm{C}$ for two days and then soaked in chloroform.

\subsection{Dialysis of UiO-66_N from DMF to Water.}

In order to avoid the formation of big aggregates during the separation of the solid from DMF, UiO-66_N were purified by dialysis. Specifically, the reaction solution of UiO-66_N in DMF was withdrawn from the reaction vial and put in a dialysis tubing. The tubing was then closed at both sides and put into a beaker with deionized water, stirring for one week. The water in the beaker was changed every day. UiO-66_N dispersion appeared as a milky and homogeneous suspension that remains stable for week at RT. SEM analysis revealed that most of the UiO-66_N were aggregated in spherical clusters of 100-200 nm average diameter, as confirmed by DLS analysis.

\subsection{Synthesis of Acridine Orange Loaded UiO-66_N (UiO-66_N@Acr)}

$50 \mathrm{mg}$ of UiO-66_N $(0.06 \mathrm{mmol})$ were first degassed overnight under vacuum and then dispersed in $5 \mathrm{~mL}$ of water. Then $5 \mathrm{mg}$ of acridine orange $(0.02 \mathrm{mmol})$ were added. The suspension was stirred at RT for three days. Then the solid was separated for centrifugation and washed three times with methanol. The amount of acridine orange absorbed by the MOF was evaluated from TGA analysis resulting in about $10 \mathrm{wt} \%$ of acridine orange absorbed from the MOF.

\subsection{Gas Sorption Measurements}

A Micromeritics 2010 apparatus (Micromeritics, Norcross, GA, USA) was used to obtain the adsorption and desorption isotherms with nitrogen at $77 \mathrm{~K}$. Before the adsorption analysis the samples were first soaked in chloroform for two days. Then they were outgassed at $100{ }^{\circ} \mathrm{C}$ under vacuum overnight. 


\subsection{TGA Analysis}

Thermogravimetric (TG) measurements were performed using a Netzsch STA490C thermoanalyser (NETZSCH Group, Selb, Germany) under a $20 \mathrm{~mL} \mathrm{~min}^{-1}$ air flux with a heating rate of $10{ }^{\circ} \mathrm{C} \mathrm{min}^{-1}$.

\subsection{Powder X-ray Diffraction}

The PXRD patterns were collected in the $3^{\circ}-60^{\circ} 2 \theta$ range and with a $40 \mathrm{~s} /$ step counting time with the $\mathrm{CuK} \alpha$ radiation on a PANalytical X'PERT PRO diffractometer (Malvern Panalytical Ltd., Malvern, UK), PW3050 goniometer (Malvern Panalytical Ltd., Malvern, UK), equipped with an X'Celerator detector (Malvern Panalytical Ltd., Malvern, UK). The long fine focus (LFF) ceramic tube operated at $40 \mathrm{kV}$ and $40 \mathrm{~mA}$.

\subsection{DLS and Zeta Potential}

Size of UiO-66_N was investigated by dynamic light scattering (DLS) measurements in pure water at $20^{\circ} \mathrm{C}$. Briefly, dialyzed suspensions of UiO-66_N with or without acridine orange, prepared as reported above, were analyzed in ultrapure water at $20^{\circ} \mathrm{C}$. Analyses were performed using a Nicomp 380 ZLS photocorrelator (PSS, Santa Barbara, CA, USA) equipped with a $35 \mathrm{mWHe} / \mathrm{Ne}$ laser $(\lambda=658 \mathrm{~nm})$ and an Avalanche photodiode detector. In the same conditions, zeta potential ( $\zeta)$ was determined by measuring the electrophoretic mobility of particles at $20^{\circ} \mathrm{C}$. The scattering intensity was measured at $14^{\circ}$ scattering angle over a time course of $180 \mathrm{~s}$. The applied potential was $0.5 \mathrm{~V}$ $\mathrm{cm}^{-1}$.

\subsection{Cell Culture Conditions}

The U251 cell line was grown in DMEM with high glucose (EuroClone S.p.A., Milano, Italy) supplemented with 10\% FBS (EuroClone S.p.A., Milano, Italy), $100 \mathrm{IU} / \mathrm{mL}$ penicillin G, $100 \mathrm{\mu g} / \mathrm{mL}$ streptomycin (EuroClone S.p.A., Milano, Italy) in an $\mathrm{H}_{2} \mathrm{O}$-saturated $5 \% \mathrm{CO}_{2}$ atmosphere at $37^{\circ} \mathrm{C}$.

\subsection{Western Blotting}

Cells were cultivated as detailed in the legends of the pertinent figure, washed twice with phosphate-buffered saline (PBS) and solubilized with $20 \%$ SDS, $1 \mathrm{M}$ Tris- $\mathrm{HCl} \mathrm{pH} \mathrm{7,4,1M}$ dithiothreitol, $200 \mathrm{mM}$ PMSF, $10 \mathrm{mg} / \mathrm{mL}$ aprotinin (Gold Biotecnology, St. Louis, MO, USA), $1 \mathrm{mg} / \mathrm{mL}$ pepstatin (EuroClone S.p.A., Milano, Italy) and $5 \mathrm{mg} / \mathrm{mL}$ leupeptin (SERVA Electrophoresis $\mathrm{GmbH}$, Heidelberg, Germany). Equal amounts of cell lysates were separated through 10\% SDS page. The following antibodies were used: polyclonal anti phosphorylated (serine 473) Akt (1:1000), polyclonal anti Akt (1:1000), polyclonal anti phosphorylated (Thr202/Tyr204) Erk1/2 (1:1000), polyclonal anti total Erk1/2 (1:1000) (all from Cell Signaling Technology, Leiden, The Netherlands). The immune reaction was developed by SuperSignal West Pico Luminol/Enhancer Solution (Thermo Fisher Scientific, Waltham, MD, USA). Filters were subjected to densitometric analysis of the pertinent immune bands and their relative standard references using the software Image Studio Digit (LI-COR, Lincoln, NE, USA).

\subsection{Measurement of Cell Cycle and Apoptosis}

Cells were treated with Ethanol and UiO-66_N at $1 \mu \mathrm{g}$ for $24 \mathrm{~h}$ and $48 \mathrm{~h}$ respectively; then the culture medium was collected and centrifuged $(400 \times g, 7 \mathrm{~min})$ in order to recover cells in suspension and cells were washed two times with PBS and processed for cell cycle analysis by propidium iodide staining and flow cytometry. Briefly, the cells were resuspended in $0.4 \mathrm{~mL}$ of hypotonic fluorochrome solution $(50 \mu \mathrm{g} / \mathrm{mL}$ propidium iodide in $0.1 \%$ sodium citrate plus $0.1 \%$ Triton X-100) in $12 \times 75-\mathrm{mm}$ polypropylene tubes (BD Biosciences Italy, Milano, Italy). The tubes were kept at $4{ }^{\circ} \mathrm{C}$ for at least $30 \mathrm{~min}$ before flow cytometric analysis. The propidium iodide fluorescence of individual nuclei was measured using a FACScan flow cytometer (BD Biosciences Italy, Milano, Italy) at $488 \mathrm{~nm}$. The percentages 
of cells in G0/G1, S, and G2/M phases and apoptotic cells were calculated using Cell FIT cell cycle analysis version 2.0.2 software.

\subsection{Scratch/Wound Healing Assay}

Cells were grown to confluent monolayer and, when the confluence reached the $100 \%$, the surface was scratched as uniformly as possible with a pipette tip forming a wound. This initial scratch and the movement of the cells into the wound area were photographed using the Olympus IX51 microscope (Olympus, Tokyo, Japan) with a $4 \times$ magnification until the wound area of the control sample was definitively closed. The size of the wound's area of all samples was calculated at each time point using the open source software ImageJ (National Institutes of Health, Bethesda, MD, USA). Two independent series of experiments were performed for each cell line.

\subsection{Internalization of UiO-66_N by U251 Glioblastoma Cell Line}

One hundred thousand cells were seeded into $35 \mathrm{~mm}$ Petri dish plates (Thermo Fisher Scientific, Waltham, MD, USA) in complete medium. After $24 \mathrm{~h}$ the medium was renewed and ethanol and UiO-66_N@Acr at the final concentration of $30 \mu \mathrm{g} / \mathrm{mL}$ were added. After $24 \mathrm{~h}$ and $48 \mathrm{~h}$, the culture medium was discharged, cells washed five times with PBS, detached with trypsin/EDTA $(0.1 \%)$, collected and centrifuged $(400 \times g, 7 \mathrm{~min})$. The cells were resuspended in $0.4 \mathrm{~mL}$ of PBS and tubes were kept at $4{ }^{\circ} \mathrm{C}$ for at least $30 \mathrm{~min}$ before flow cytometric analysis. The UiO-66_N@Acr fluorescence of individual cells was detected with Coulter Epics XL-MCL flow cytometer (Beckman Coulter, Brea, CA, USA) and data were analyzed using FlowJo software (TreeStar, Ashland, OR, USA).

\subsection{MTT Viability Assay}

Cells were seeded in 96 well plates with a cell density of $4 \times 10^{3}$ and after $24 \mathrm{~h}$ in culture were treated with UiO-66_N in pure water at the final concentrations of $0.1,0.5,1,5$ and $10 \mu \mathrm{g} / \mathrm{mL} .24$ and $48 \mathrm{~h}$ later, cells were incubated with the 3-(4,5-Dimethylthiazol-2-yl)-2,5-Diphenyltetrazolium Bromide (MTT) solution (Sigma Aldrich ${ }^{\circledR}$, St. Louis, MO, USA) for four hours and after this incubation period, a water-insoluble formazan dye was formed. After solubilisation, the formazan dye was quantified using a LabSystems Multiskan MS spectrophotometer at $550 \mathrm{~nm}$ (Artisan Technology Group (), Champaign, IL, USA). Each experiment was performed in triplicate.

\subsection{FURA-2 Calcium Imaging Assay}

U251 cells were plated at the concentration of $1.5 \times 10^{3}$ cells $/ \mathrm{mL}$ and used on the third day of culture. Before experiments, cells were incubated with FURA-2 AM ( $3 \mu \mathrm{M}$; Sigma-Aldrich, Sigma Aldrich ${ }^{\circledR}$, St. Louis, MO, USA) for $45 \mathrm{~min}$ and extensively washed with a Ringer solution of the following composition (in $\mathrm{mM}$ ): $\mathrm{NaCl} 106.5, \mathrm{KCl} 5, \mathrm{CaCl}_{2} 2, \mathrm{MgCl}_{2} 2$, MOPS 5, glucose 20, Na gluconate 30, at pH 7.25 (all from Sigma Aldrich ${ }^{\circledR}$, St. Louis, MO, USA). Cells were continuously perfused using a gravity-drive perfusion system, with tubing connected to a final tip of 100 to $200-\mu \mathrm{m}$ diameter focally oriented onto the field of interest. UiO-66_N were added at the concentration of $1 \mu \mathrm{g} / \mathrm{mL}$ after $9 \mathrm{~min}$ of perfusion for $8 \mathrm{~min}$. A standard control pressure perfused the cells for about $20 \mathrm{~min}$ with only the Ringer solution. A positive control pressure perfused a solution of ionomycin calcium salt (Tocris Bioscience, Bristol, UK) for about $7 \mathrm{~min}$. The estimation of intracellular free $\mathrm{Ca}^{2+}$ concentration was reported as change of the ratio between fluorescence emission at $510 \mathrm{~nm}$, obtained with 340 and 380-nm excitation wavelengths (optical filters and dichroic beam splitter were from Lambda DG4, Shutter Instruments, Novato, CA, USA). Ratiometric data was randomly acquired from 30 cells every $3 \mathrm{~s}$.

\subsection{Microscopic Fluorescence Observation and Analysis}

All the imaging analyses have been conducted with an upright fluorescence microscope (Axiozoom V16, Zeiss, Oberkochen, Germania); all the images are snapped with a digital camera 
(Axiocam 502 mono, Zeiss, Oberkochen, Germania) and elaborated with ZEN 2 software (Zeiss, Oberkochen, Germania).

\subsection{Statistical Analysis}

Each experiment was performed at least three times and data are expressed as mean values \pm SEM. Data were subjected variance (ANOVA) analysis using a statistical GraphPad Prism, version 7.00 software package (GraphPad Software, La Jolla, CA, USA).

\section{Results}

UiO-66_N was synthesized in a nanometric form according to a modified synthetic procedure [22]. This synthesis produced UiO-66_N nanocrystals in the low nanometric range with an average size around $25 \mathrm{~nm}$. To the best of our knowledge, this is the first report on ultrasmall MOFs being investigated for their cell internalization capacity.

Figure 1A displays the XRPD patterns of UiO-66_N with $100 \mathrm{~nm}$ average particle size (1); showed for comparison, of UiO-66_N (25 nm average particle size) (2); UiO-66_N soaked overnight in chloroform (3); and UiO-66_N loaded with acridine-orange (4). The average crystal size was estimated by applying the Scherrer formula on the 111, 200 and 220 peaks after analytical deconvolution and by correcting the instrumental broadening with a line profile standard $\left(\mathrm{LaB}_{6}\right)$, according to a procedure already applied for similar materials [36]. For the nanometric samples the average crystalline domain size obtained, after the application of the Scherrer formula, was $15 \mathrm{~nm}$. A drastic broadening of the peaks, in agreement with very small crystalline domains, was indeed observed. From the comparison of patterns (1) and (2), it can be seen that the structure of UiO-66-N is fully retained although an important peak broadening is observed. The soaking in chloroform was used in order to remove the residual DMF solvent molecules, the successive acridine inclusion did not change the X-ray pattern. The amount of acridine loaded is about $10 \mathrm{wt} \%$ as calculated from the TGA analysis (Figure S1). The nitrogen adsorption isotherm of UiO-66_N is shown in Figure 1B and the BET surface area is $736 \mathrm{~m}^{2} / \mathrm{g}$. The hysteresis of the desorption curve is indicative of the presence of mesopores probably due to interparticle contacts. The micropore surface area is $411 \mathrm{~m}^{2} / \mathrm{g}$ (pore volume of $0.17 \mathrm{~cm}^{3} / \mathrm{g}$ ), whereas the external surface area is about $325 \mathrm{~m}^{2} / \mathrm{g}$. These results are in good agreement with those recently reported on UiO-66 nanocrystals with size around $20 \mathrm{~nm}[22,23]$. The value of the external surface area is about 5 to 10 times higher than that normally measured for UiO-66_N samples with average crystalline size $>100 \mathrm{~nm}$. However, an important reduction of the internal surface area (more than a half) compared to that normally measured for crystalline UiO-66_N (around $1000 \mathrm{~m}^{2} / \mathrm{g}$ ) was observed.

Figure 2a,b show the TEM and FE-SEM images of UiO-66_N obtained by direct synthesis. They appear to be strongly aggregated but their size has a homogeneous distribution centered around $30 \mathrm{~nm}$, which is a value slightly higher than that found by XRPD data (see Figure S2). However, the broadening of the $\mathrm{X}$-ray peaks also takes into account the presence of defects resulting in a larger broadening than that only related to the crystal size. Another SEM image of UiO-66N is placed in Supporting Information (Figure S7) Figure 2c shows the UiO-66_N separated from DMF by dialysis and loaded with acridine. The picture was taken from the sample dried from the water dispersion after dialysis. The small particles are aggregated into spherical structures of 100 to $200 \mathrm{~nm}$ size. These spherical structures are also aggregated in larger clusters being attached each other. Photo correlation spectroscopy (Figure 2d) confirmed the observed formation of large aggregates especially for UiO-66_N@Acr. The dialyzed suspensions showed populations with mean hydrodynamic diameters of $65 \mathrm{~nm}$ and $345 \mathrm{~nm}$ with large aggregates at size $>5000 \mathrm{~nm}$ and $1000 \mathrm{~nm}$ for UiO-66_N@Acr and UiO-66_N, respectively. Such findings clearly highlight once more the tendency of UiO-66_N to aggregate in water, matching the TEM observations on the non-dialyzed sample. Even though more dispersed than UiO-66_N, the presence of a smaller particle population for UiO-66_N@Acr particles may suggest that a change in surface properties due to acridine orange 
adsorption could prevent to some extent aggregation. Such a modification is proved by the change measured in the $\xi$ value that changed from negative $(-14.8 \mathrm{mV})$ for UiO-66_N to slightly positive $(+4.1 \mathrm{mV})$ for UiO-66_N@acr as a result of the presence of acridine on the surface of the particles. Therefore, acridine may produce some small repulsion able to partially reduce particle agglomeration.
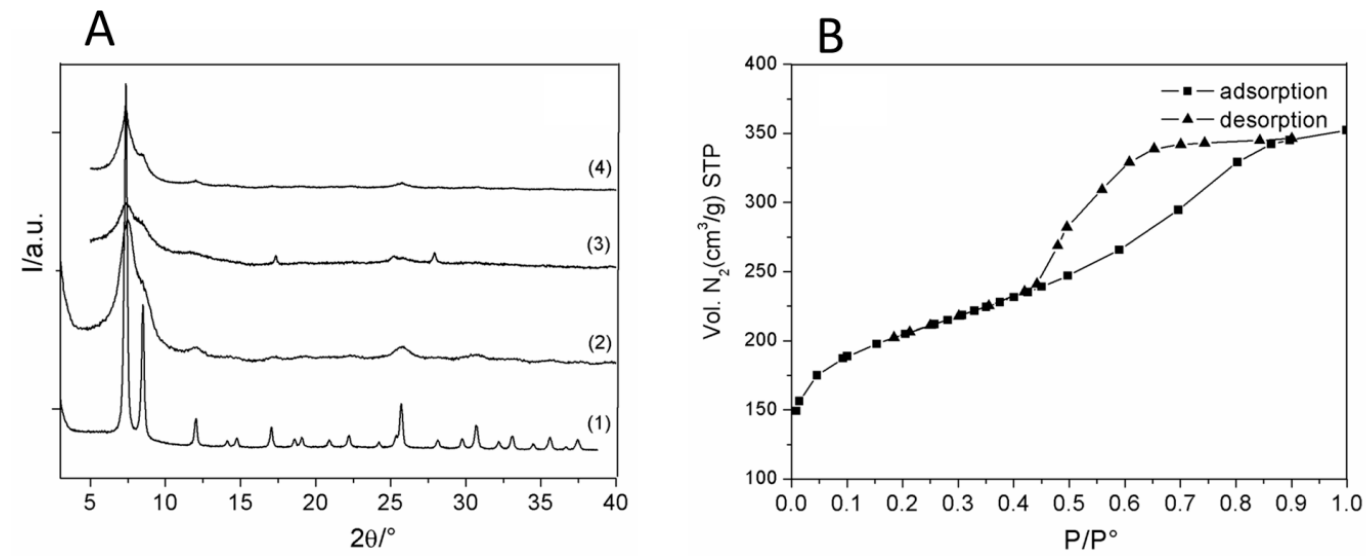

Figure 1. (A) XRPD patterns for UiO-66_N 100 (1), UiO-66_N (2), UiO-66_N soaked overnight in chloroform (3), and UiO-66_N@Acr (4); (B) $\mathrm{N}_{2}$ adsorption-desorption isotherms for sample UiO-66_N measured at $100 \mathrm{~K}$.
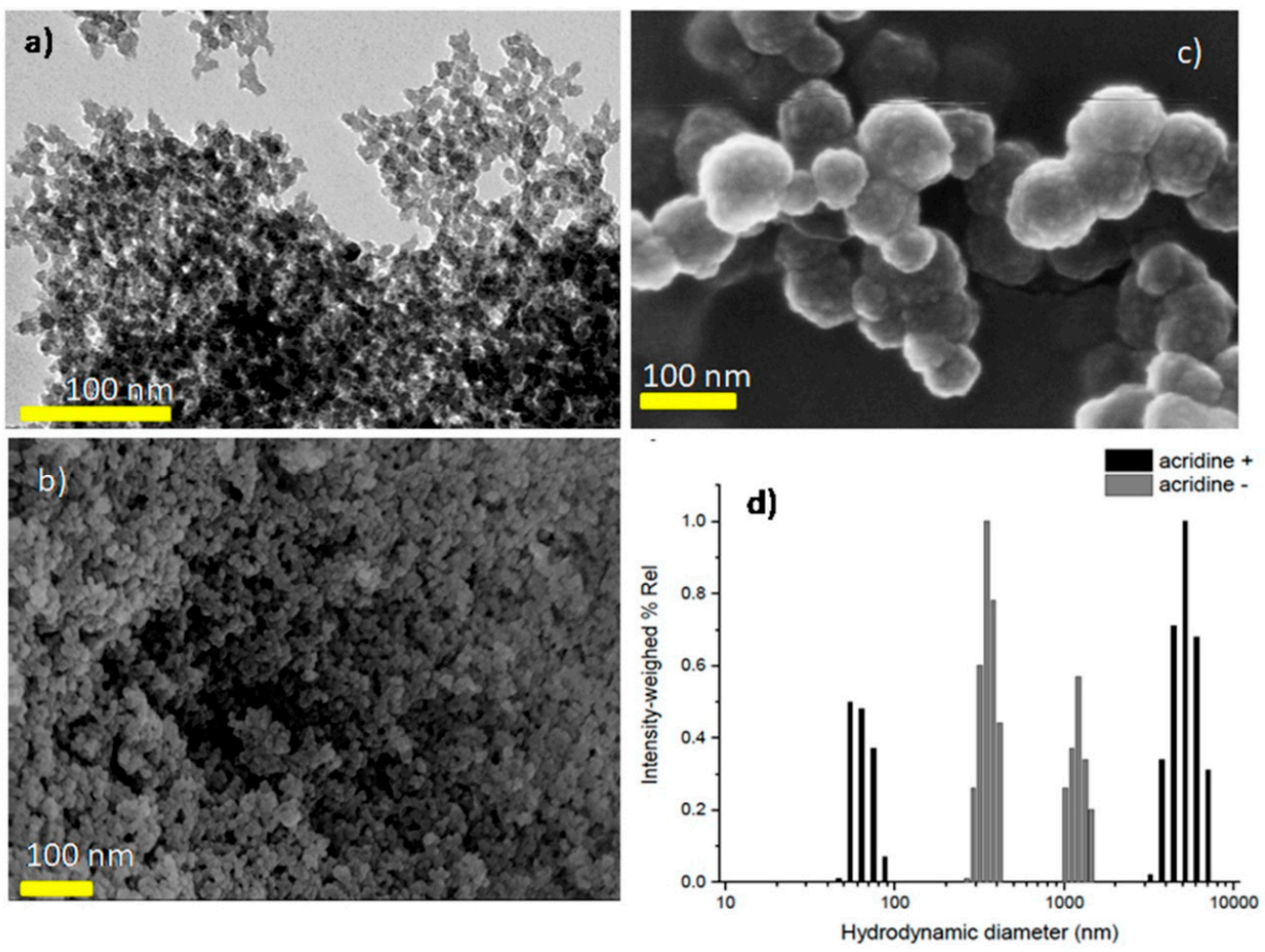

Figure 2. (a) TEM and (b) FE-SEM images of UiO-66_N obtained by hydrothermal synthesis; (c) spherical particles aggregates of smaller UiO-66_N@Acr obtained by dialysis; and (d) photo correlation spectroscopy measurements depicting hydrodynamic populations for UiO-66_N (grey) and UiO-66_N@Acr (black) in pure water at $20^{\circ} \mathrm{C}$.

In order to check the acridine adsorption/inclusion degree inside the MOF structure, the effective release of such a dye in PBS (which simulate the cell culture conditions) was studied by UV-vis spectroscopy. UV-vis spectra of UiO-66_N@Acr dispersed in PBS (about $2 \mathrm{mg} / \mathrm{mL}$ ) are shown in Figure S3. After $24 \mathrm{~h}$ and $48 \mathrm{~h}$, no acridine absorption signal could be detected suggesting that 
no molecules were released from the MOFs. This experimental evidence excludes the presence of free acridine molecules into the cells over the entire incubation timeframe. As our main interest is directed toward pharmaceutical applications, the biological inertness of our MOFs must be a pivotal feature. Since no acridine molecules are released from the MOF, we have evaluated the UiO-66_N@Acr incorporation in U251 cells. After $48 \mathrm{~h}$ of $30 \mu \mathrm{g} / \mathrm{mL}$ UiO-66_N@Acr treatment, the $97.9 \%$ of the cells showed fluorescence assessed by cytofluorimetry (Figure 3B) compared to untreated cells (Figure 3A) that did not show fluorescence. The same percentage of U251 fluorescent cells was shown after 24 and $72 \mathrm{~h}$ of treatment (data not shown). These results demonstrate that UiO-66_N are quickly incorporated by $\mathrm{U} 251$ cells and held permanently inside them for at least $72 \mathrm{~h}$.

A

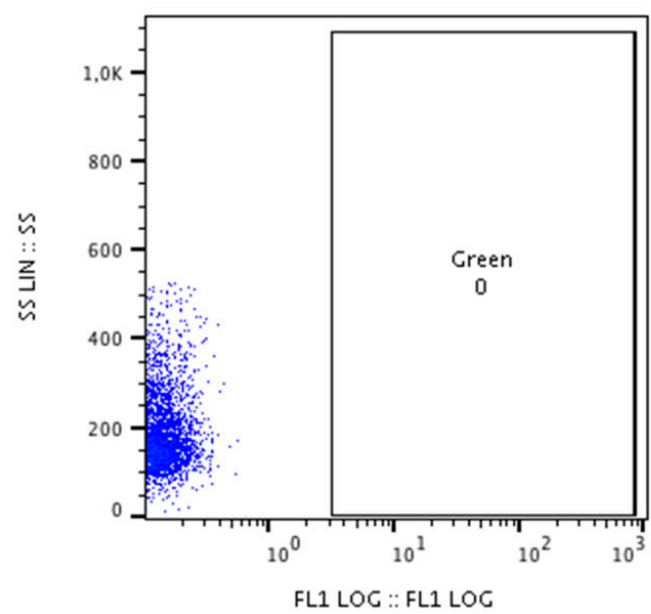

B

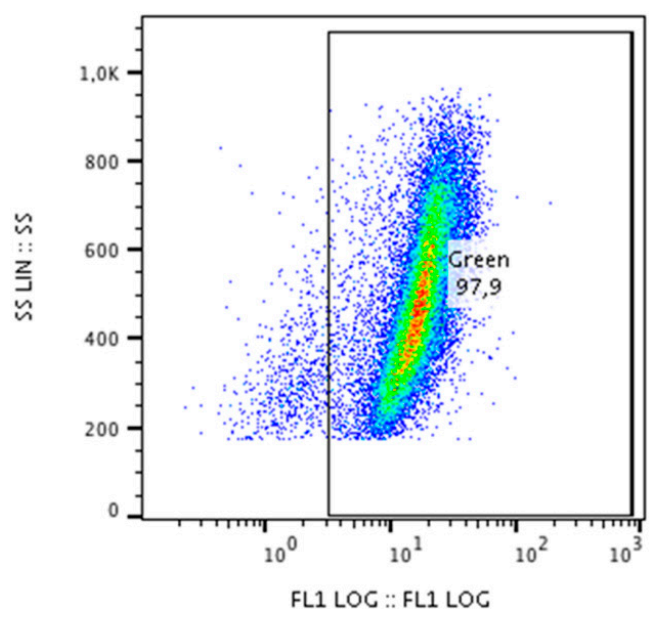

Figure 3. UiO-66_N internalization by U251 cells. (A) Not treated cells showed no fluorescence. (B) UiO-66_N@Acr treated cells showed fluorescence after $48 \mathrm{~h}$ of treatment. Fluorescent cells accounts for $97.9 \%$ of total cells.

In order to confirm UiO-66_N internalization, U251 cells were treated with UiO-66_N@Acr at the final concentration of $1 \mu \mathrm{g} / \mathrm{mL}$ for $48 \mathrm{~h}$ and observed by immunofluorescence. Before observation, excess of MOFs in the cell medium was removed by extensive washes in PBS; nuclei of cells have been marked with DAPI. Cells were observed alive in PBS. Results of fluorescence imaging are shown in Figure 4: UiO-66_N@Acr are detectable inside U251 glioblastoma cells after $2 \mathrm{~h}$ from the incubation and they are still detectable after $48 \mathrm{~h}$. The accumulation of MOFs seems to concentrate around the nuclei of the cells (Figure 4). 


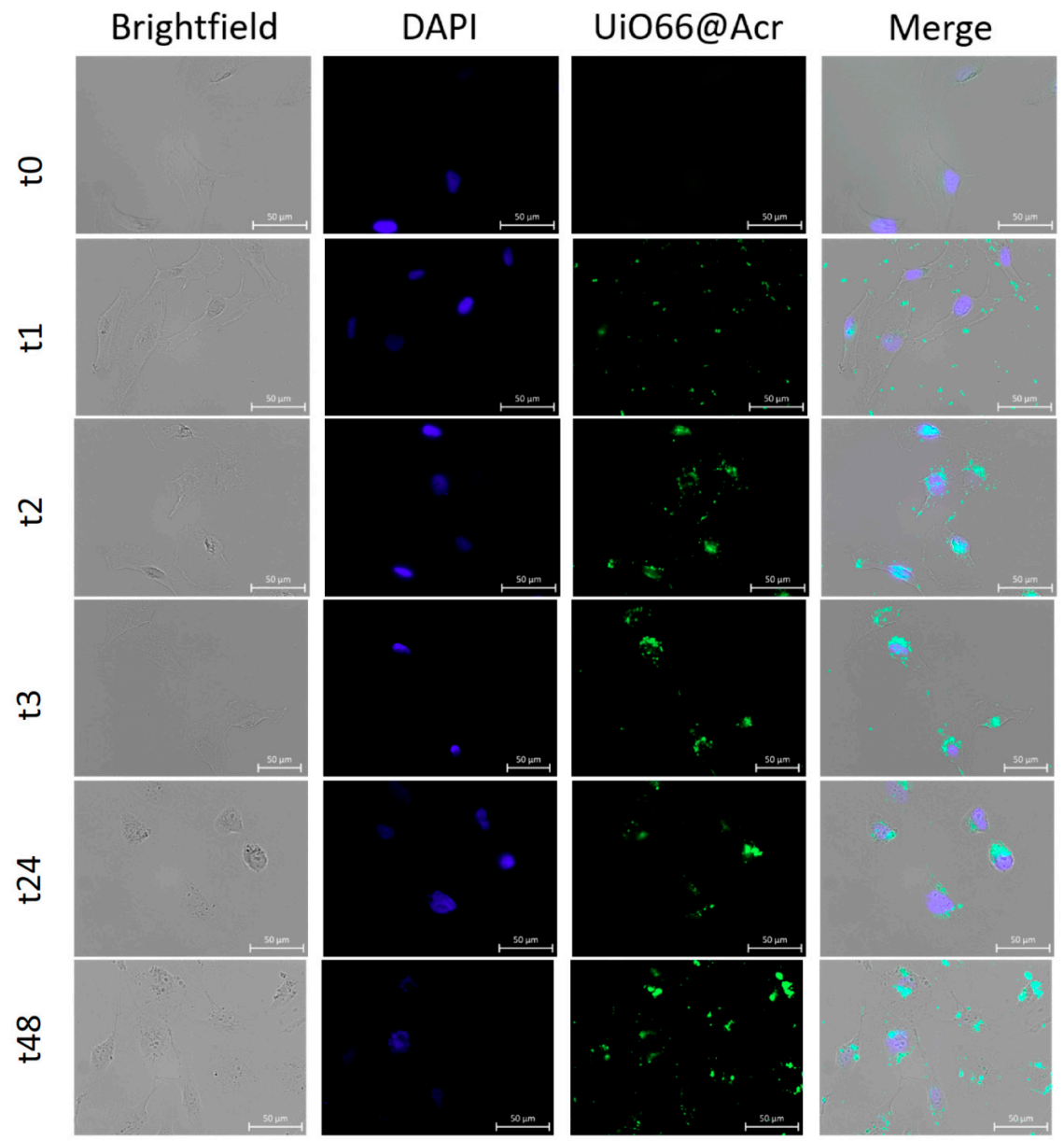

Figure 4. Fluorescence imaging of cells treated with UiO-66_N@Acr at the final concentration of $1 \mu \mathrm{g} / \mathrm{mL}$ at different times $(0,1,2,3,24$, and $48 \mathrm{~h})$ of treatment. Bar $50 \mu \mathrm{m}$

Cells have been washed with PBS and incubated with DAPI for three minutes, in order to stain cellular nuclei. Cells have been washed again before observation. Figure 5 displays the biocompatibility of UiO-66_N in terms of viability: MTT assay shows no significant changes in U251 cells viability compared to control after 24 and $48 \mathrm{~h}$ of exposition at different concentrations (Figure 5). MTT assay uses tetrazolium salt 3-(4,5-dimethyl-2-thia-zolyl)-2,5-diphenyl-2H-tetrazolium bromide) as a biological tool to measure cell viability. Reduction of MTT is associated with flavin-containing enzymes, which are well-known mitochondrial enzymes, and this demonstrates that mitochondria are the main site of MTT reduction. Thus, UiO-66_N do not alter cell viability and do not interfere with the mitochondrial activity of the cells.
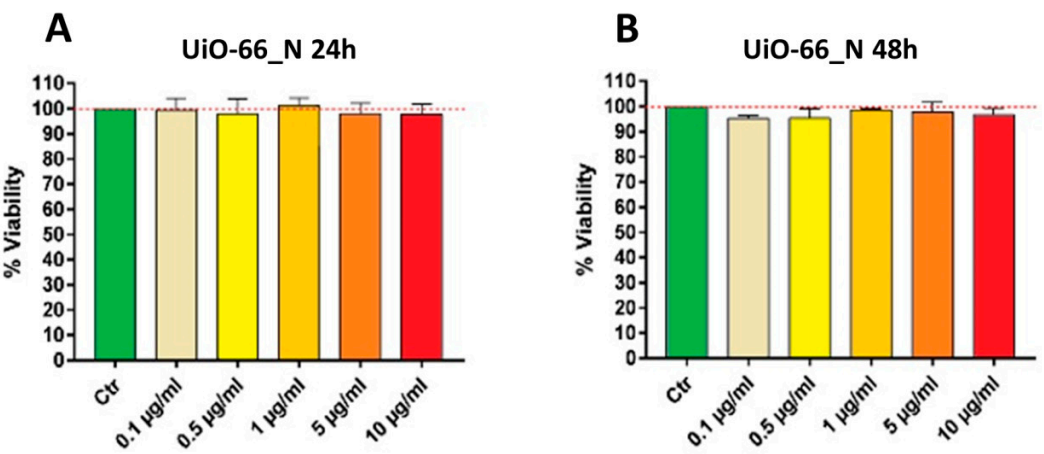

Figure 5. U251 cells viability by MTT assay, after 24 (A) and 48 (B) hours of incubation with UiO-66_N at various concentrations. 
As calcium plays an important role in cell physiology, a ratiometric intracellular calcium concentration measurement with the FURA-2 assay following acute treatment with UiO-66_N was performed. Data shown in Figure S4, displays no significant changes in the intracellular calcium concentration following the application of $1 \mu \mathrm{g} / \mathrm{mL}$ on UiO-66_N; Similar results were obtained with the higher concentration of $10 \mu \mathrm{g} / \mathrm{mL}$ UiO-66_N (Figure S5). The FURA2 assay was conducted even without MOF perfusing, as an assay control showing no differences with the previously described experiment. Such data support further MOF biocompatibility.

Having demonstrated that UiO-66_N are quickly incorporated, the cell cycle of U251 cells to exclude UiO-66_N effects on cell cycle machinery was evaluated. Propidium iodide staining shows no significant differences between not treated and MOF-treated cells (Figure 6), further confirming that they are a biocompatible and an inert nanomaterial. In accordance with these findings, the percentage of cell distribution in G0/G1, S, and G2/M phases was not modified between not treated and MOF-treated cells (data not shown).

A

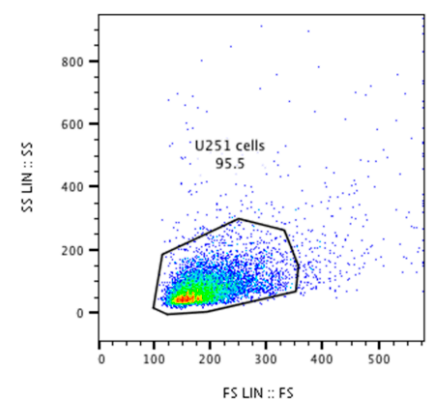

C

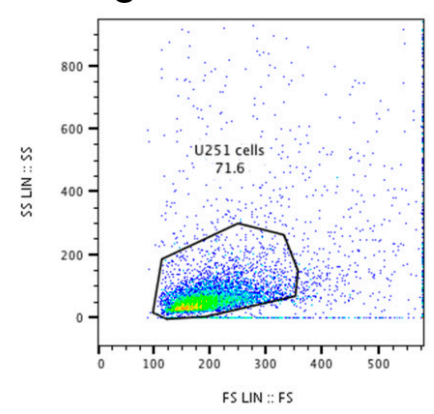

B

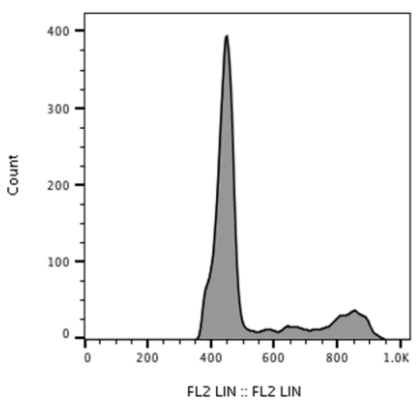

D

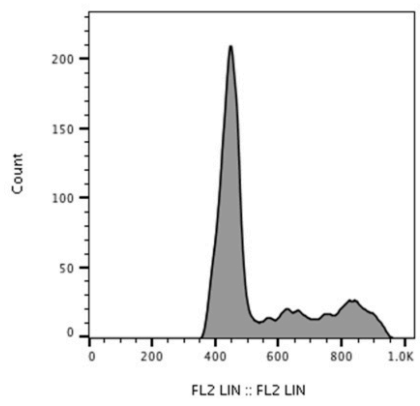

Figure 6. Flow cytometry analysis of not treated (A,B) or treated (C,D) U251 cells with UiO-66_N (30 $\mu \mathrm{g} / \mathrm{mL}$ ) for $48 \mathrm{~h}$. Left panels represent dot plot of not treated (A) and UiO-66_N treated (C) live U251 cells (gated inside the dot plot). Events outside the gate of U251 cells in UiO-66_N-treated group are mostly MOF aggregates. Right panels represent propidium iodide staining showing cell cycle profiles. No significant differences between not treated (B) and UiO-66_N treated (D) cells were detected.

Moreover, by FACS analysis, we measured the percentage of apoptotic cells in UiO-66_N (20 or $50 \mu \mathrm{g} / \mathrm{mL}$ ) treated U251 cells compared to not treated cells (Figure 7). After $48 \mathrm{~h}$ of treatment, the percentage of apoptotic U251 cells in treated and not treated cells was similar, with slight not statistically significant differences. These results demonstrate that in U251 cells UiO-66_N does not affect apoptosis. 
A

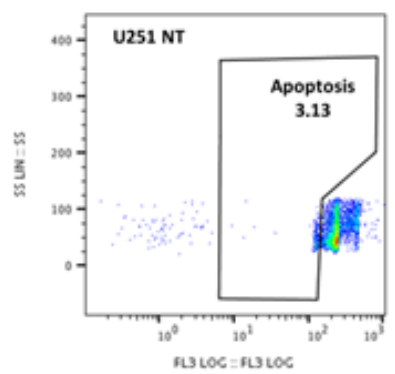

B

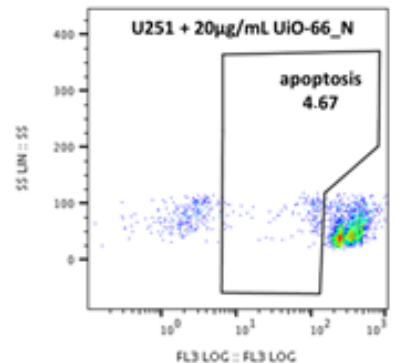

C

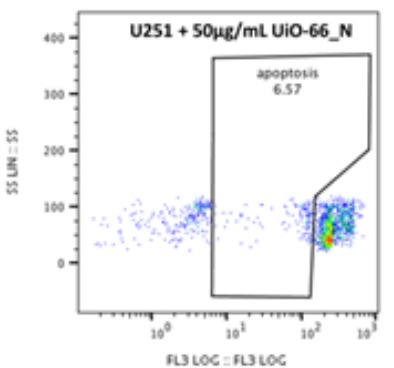

Figure 7. UiO-66_N administration does not induce apoptosis in U251 cells. Flow cytometry analysis of not treated (A) or treated U251 cells with 20 (B) or 50 (C) $\mu \mathrm{g} / \mathrm{mL}$ UiO-66_N for $48 \mathrm{~h}$. Numbers inside the gates represent percentage of apoptotic U251 cells assessed by propidium iodide staining.

In GBM, high level of phosphorylated AKT has been reported to correlate with a poor prognosis [36]. Epidermal growth factor receptor (EGFR) amplification and/or overexpression occurs in $40-50 \%$ of GBM [30] and leads to the activation of PI3K/AKT signaling pathway. [36]. Thus, inhibition of this pathway seems to be a promising target for developing more effective GBM therapies. However, the modest efficacy of these approaches observed in the clinical trials conducted so far, suggests that they might be more effective in combination with other agents. [37] In GBM, EGFR overexpression also activates the extracellular signal-regulated kinases 1 and 2 (ERK1/2), [32] proteins belonging to the mitogen-activated protein kinase (MAPK) family contributing to the highly altered phenotype of this tumor cells. UiO-66_N did not affect Akt and ERK1/2 phosphorylation level in U251 glioblastoma cells. From a metabolic point of view UiO-66_N showed a completely inert behavior (Figure 8).

A

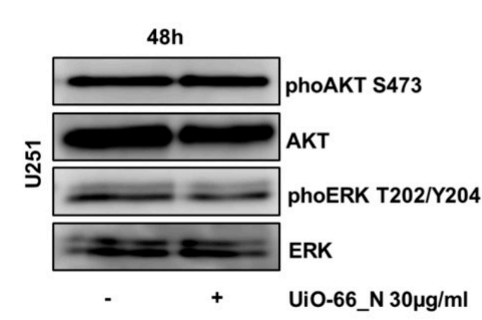

B

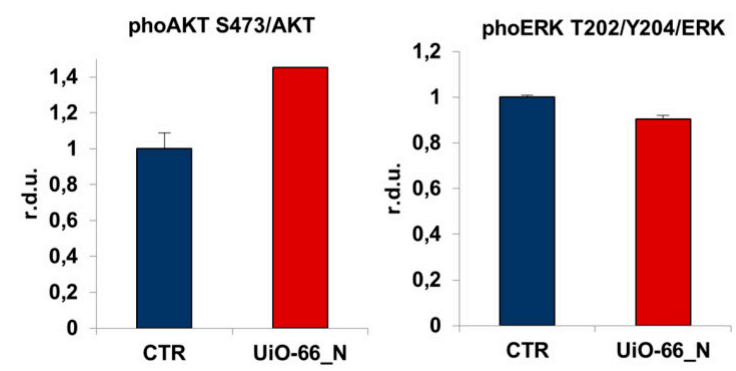

Figure 8. UiO-66_N do not affect Akt and ERK1/2 phosphorylation in U251 glioblastoma cells. Western blots (A) and densitometric quantification of Akt and ERK1/2 phosphorylation levels (B). The cells were treated with $30 \mu \mathrm{g} / \mathrm{mL}$ UiO-66_N for $48 \mathrm{~h}$. Blots are representative of at least three experiments. The difference in phoAkt level is not statistically significant.

Invasiveness is considered as a major determinant for malignant behavior in human gliomas and U251 cells represent a highly invasive tumor [38]. For this reason, the involvement of UiO-66_N in influencing migration properties was investigated. In order to avoid filling up of the wound by proliferating rather than migrating cells, these tests were conducted under non-proliferative conditions. As expected, UiO-66_N did not affect U251 cell migration evaluated by wound healing assay, compared to not treated cells (Figure S6). It is noteworthy that glioblastoma infiltration is an extremely complex phenomenon that also requires the steady support of extracellular cues [39]. Our preliminary data demonstrate that UiO-66_N do not affect this phenomenon.

\section{Conclusions}

UiO-66 nanocrystals of ultrasmall size were synthesized and tested for the first time on glioblastoma U251 cells in order to evaluate their biocompatibility and internalization mechanism. 
The UiO-66 $\mathrm{N}$ were used without any surface modification. The particles separated from the mother liquors tend to strongly aggregate and they cannot be easily stabilized in water dispersion. However, dialysis of the NPs from the DMF solution to water allows to obtain stable dispersion of $100 \mathrm{~nm}$ spherical aggregates. Despite the absence of surface modification, nude UiO-66_N are avidly internalized by GBM cells and retained within them. No morphological changes or decrease in cell viability were highlighted. Similarly, the cell cycle, the apoptosis as well as the migration capacity were not altered. From a metabolic point of view, neither changes in mitochondrial activity nor alterations of fundamental transduction pathways were evidenced. Ultimately UiO-66_N are ideal for drug and active molecule delivery towards GBM cells. The treatment of GBM represents a very complex challenge and new strategies must be put into place. Nanomedicine can provide new opportunity for this disease. To date, different NPs have been utilized for drug delivery in GBM, through different administration routes [40]. Various criticisms, such as restricted passage across the blood-brain barrier, have been highlighted. Moreover, GBM are characterized by high infiltrative ability and the potential therapeutics should not only be able to pass through the blood-brain barrier but also should be able to diffuse within the brain. In this context, future studies will have to address not only the brain accumulation and infiltration capacity of these NP but also strategies to grant selectivity with respect to GBM. If successful, ultrasmall UiO-66_N may lead to new treatment approaches for GBM treatment.

Supplementary Materials: The following are available online at http:/ /www.mdpi.com/2079-4991/8/11/867/s1, Figure S1: TGA curves of UiO-66_N (blue line) and UiO-66_N@Acr (orange line); Figure S2: Size distribution of UiO-66_N obtained by direct synthesis; Figure S3: UV-vis spectra in simulated body fluids (SBF) of acridine orange (orange line), UiO-66_N@Acr (red line) and SBF surnatant after $24 \mathrm{~h}$ and 48 h; Figure S4: Calcium channels activation in untreated cells; Figure S5: Calcium channels activation during treatment with UiO-66_N; Figure S6: Wound healing assay of U251 cells; Figure S7: High magnification FE-SEM image of UiO-66_N.

Author Contributions: Conceptualization, C.A., S.B., S.G., R.D., and F.C.; Data curation, S.B., S.G., O.B. and B.F.; Funding acquisition, B.F.; Investigation, L.M., F.R., C.M., and O.B.; Writing-original draft, C.A. and F.C.

Funding: This work was funded by Ministero dell'Istruzione, dell'Università e della Ricerca, Italy (SIR RBSI144EUA) to B.F., Fondazione Cassa di Risparmio di Perugia (2014.0254.021) to C.A.

Acknowledgments: The authors thank Fabio Marmottini for the gas-sorption measurements.

Conflicts of Interest: The authors declare no conflict of interest.

\section{References}

1. Cho, K.; Wang, X.; Nie, S.; Chen, Z.G.; Shin, D.M. Therapeutic nanoparticles for drug delivery in cancer. Clin. Cancer. Res. 2008, 14, 1310-1316. [CrossRef] [PubMed]

2. Poljaková, J.; Eckschlager, T.; Hřebačková, J.; Hraběta, J.; Stiborová, M. The comparison of cytotoxicity of the anticancer drugs doxorubicin and ellipticine to human neuroblastoma cells. Interdiscip. Toxicol. 2008, 1, 186-189. [CrossRef] [PubMed]

3. Chen, G.; Roy, I.; Yang, C.; Prasad, P.N. Nanochemistry and Nanomedicine for Nanoparticle-based Diagnostics and Therapy. Chem. Rev. 2016, 116, 2826-2885. [CrossRef] [PubMed]

4. Wicki, A.; Witzigmann, D.; Balasubramanian, V.; Huwyler, J. Nanomedicine in cancer therapy: Challenges, opportunities, and clinical applications. J. Control. Release 2015, 200, 138-157. [CrossRef] [PubMed]

5. Janib, S.M.; Moses, A.S.; MacKay, J.A. Imaging and drug delivery using theranostic nanoparticles. Adv. Drug. Deliv. Rev. 2010, 62, 1052-1063. [CrossRef] [PubMed]

6. Zhang, J.; Atay, T.; Nurmikko, A.V. Optical detection of brain cell activity using plasmonic gold nanoparticles. Nano Lett. 2009, 9, 519-524. [CrossRef] [PubMed]

7. Lengert, E.; Saveleva, M.; Abalymov, A.; Atkin, V.; Wuytens, P.C.; Kamyshinsky, R.; Vasiliev, A.L.; Gorin, D.A.; Sukhorukov, G.B.; Skirtach, A.G.; et al. Silver Alginate Hydrogel Micro- and Nanocontainers for Theranostics: Synthesis, Encapsulation, Remote Release, and Detection. ACS. Appl. Mater. Interfaces 2017, 9, 21949-21958. [CrossRef] [PubMed]

8. Filippousi, M.; Altantzis, T.; Stefanou, G.; Betsiou, M.; Bikiaris, D.N.; Angelakeris, M.; Pavlidou, E.; Zamboulis, D.; Van Tendeloo, G. Polyhedral iron oxide core-shell nanoparticles in a biodegradable polymeric 
matrix: Preparation, characterization and application in magnetic particle hyperthermia and drug delivery. RSC Adv. 2013, 3, 24367-24377. [CrossRef]

9. Blanco, E.; Shen, H.; Ferrari, M. Principles of nanoparticle design for overcoming biological barriers to drug delivery. Nat. Biotechnol. 2015, 33, 941-951. [CrossRef] [PubMed]

10. Della Rocca, J.; Liu, D.; Lin, W. Nanoscale metal-organic frameworks for biomedical imaging and drug delivery. Acc. Chem. Res. 2011, 44, 957-968. [CrossRef] [PubMed]

11. Wu, M.X.; Yang, Y.W. Metal-organic Framework (MOF)-Based Drug/Cargo Delivery and Cancer Therapy. Adv. Mater. 2017, 29, 1606134. [CrossRef] [PubMed]

12. Horcajada, P.; Serre, C.; Vallet-Regí, M.; Sebban, M.; Taulelle, F.; Férey, G. Metal-organic frameworks as efficient materials for drug delivery. Angew. Chem. Int. Ed. 2006, 45, 5974-5978. [CrossRef] [PubMed]

13. Horcajada, P.; Gref, R.; Baati, T.; Allan, P.K.; Maurin, G.; Couvreur, P.; Férey, G.; Morris, R.E.; Serre, C. Metal-organic frameworks in biomedicine. Chem. Rev. 2012, 112, 1232-1268. [CrossRef] [PubMed]

14. Yaghi, O.M.; O'Keeffe, M.; Ockwig, N.W.; Chae, H.K.; Eddaoudi, M.; Kim, J. Reticular synthesis and the design of new materials. Nature 2003, 423, 705-714. [CrossRef] [PubMed]

15. Kitagawa, S.; Kitaura, R.; Noro, S. Functional porous coordination polymers. Angew. Chem. Int. Ed. 2004, 43, 2334-2375. [CrossRef] [PubMed]

16. Férey, G. Hybrid, porous solids: Past, present, future. Chem. Soc. Rev. 2008, 37, 191-214. [CrossRef] [PubMed]

17. Tamames-Tabar, C.; Imbuluzqueta, E.; Guillou, N.; Serre, C.; Miller, S.R.; Elkaïm, E.; Horcajada, P.; Blanco-Prieto, M.J. A Zn azelate MOF: Combining antibacterial effect. Cryst. Eng. Comm. 2015, 17, 456-462. [CrossRef]

18. Filippousi, M.; Turner, S.; Leus, K.; Siafaka, P.I.; Tseligka, E.D.; Vandichel, M.; Nanaki, S.G.; Vizirianakis, I.S.; Bikiaris, D.N.; Van Der Voort, P.; et al. Biocompatible Zr-based nanoscale MOFs coated with modified poly ( $\varepsilon$-caprolactone) as anticancerdrug carriers. Int. J. Pharm. 2016, 509, 208-218. [CrossRef] [PubMed]

19. Bai, Y.; Dou, Y.; Xie, L.H.; Rutledge, W.; Li, J.R.; Zhou, H.C. Zr-based metal-organic frameworks: Design, synthesis, structure, and applications. Chem. Soc. Rev. 2016, 45, 2327-2367. [CrossRef] [PubMed]

20. Cavka, J.H.; Jakobsen, S.; Olsbye, U.; Guillou, N.; Lamberti, C.; Bordiga, S.; Lillerud, K.P. A new zirconium inorganic building brick forming metal organic frameworks with exceptional stability. J. Am. Chem. Soc. 2008, 130, 13850-13851. [CrossRef] [PubMed]

21. Wu, H.; Chua, Y.S.; Krungleviciute, V.; Tyagi, M.; Chen, P.; Yildirim, T.; Zhou, W. Unusual and highly tunable missing-linker defects in zirconium metal-organic framework UiO-66 and their important effects on gas adsorption. J. Am. Chem. Soc. 2013, 135, 10525-10532. [CrossRef] [PubMed]

22. Taddei, M.; Dümbgen, K.C.; van Bokhoven, J.A.; Ranocchiari, M. Aging of the reaction mixture as a tool to modulate the crystallite size of UiO-66 into the low nanometer range. Chem. Commun. 2016, 52, 6411-6414. [CrossRef] [PubMed]

23. Donnadio, A.; Narducci, R.; Casciola, M.; Marmottini, F.; D'Amato, R.; Jazestani, M.; Chiniforoshan, H.; Costantino, F. Mixed Membrane Matrices Based on Nafion/UiO-66/SO 3 H-UiO-66 Nano-MOFs: Revealing the Effect of Crystal Size, Sulfonation, and Filler Loading on the Mechanical and Conductivity Properties. ACS. Appl. Mater. Interfaces 2017, 9, 42239-42246. [CrossRef] [PubMed]

24. Li, Y.A.; Zhao, C.W.; Zhu, N.X.; Liu, Q.K.; Chen, G.J.; Liu, J.B.; Zhao, X.D.; Ma, J.P.; Zhang, S.; Dong, Y.B. Nanoscale UiO-MOF-based luminescent sensors for highly selective detection of cysteine and glutathione and their application in bioimaging. Chem. Commun. 2015, 51, 17672-17675. [CrossRef] [PubMed]

25. Orellana-Tavra, C.; Mercado, S.A.; Fairen-Jimenez, D. Endocytosis Mechanism of Nano Metal-organic Frameworks for Drug Delivery. Adv. Healthc. Mater. 2016, 5, 2261-2270. [CrossRef] [PubMed]

26. Abánades Lázaro, I.; Haddad, S.; Sacca, S.; Orellana-Tavra, C.; Fairen-Jimenez, D.; Forgan, R.S. Selective Surface PEGylation of UiO-66 Nanoparticles for Enhanced Stability, Cell Uptake, and pH-Responsive Drug Delivery. Chem 2017, 2, 561-578. [CrossRef] [PubMed]

27. Wang, L.; Wang, W.; Zheng, X.; Li, Z.; Xie, Z. Nanoscale Fluorescent Metal-organic Framework@Microporous Organic Polymer Composites for Enhanced Intracellular Uptake and Bioimaging. Chem. Eur. J. 2017, 23, 1379-1385. [CrossRef] [PubMed]

28. Orellana-Tavra, C.; Baxter, E.F.; Tian, T.; Bennett, T.D.; Slater, N.K.; Cheetham, A.K.; Fairen-Jimenez, D. Amorphous metal-organic frameworks for drug delivery. Chem. Commun. 2015, 51, 13878-13881. [CrossRef] [PubMed] 
29. Orellana-Tavra, C.; Marshall, R.J.; Baxter, E.F.; Lázaro, I.A.; Tao, A.; Cheetham, A.K.; Forgan, R.S.; Fairen-Jimenez, D. Drug delivery and controlled release from biocompatible metal-organic frameworks using mechanical amorphization. J. Mater. Chem. B. 2016, 4, 7697-7707. [CrossRef]

30. Wu, Y.; Han, J.; Xue, P.; Xu, R.; Kang, Y. Nano metal-organic framework (NMOF)-based strategies for multiplexed microRNA detection in solution and living cancer cells. Nanoscale 2015, 7, 1753-1759. [CrossRef] [PubMed]

31. Arcuri, C.; Fioretti, B.; Bianchi, R.; Mecca, C.; Tubaro, C.; Beccari, T.; Franciolini, F.; Giambanco, I.; Donato, R. Microglia-glioma cross-talk: A two way approach to new strategies against glioma. Front. Biosci. 2017, 22, 268-309. [CrossRef]

32. Ostrom, Q.T.; Gittleman, H.; Liao, P.; Vecchione-Koval, T.; Wolinsky, Y.; Kruchko, C.; Barnholtz-Sloan, J.S. CBTRUS Statistical Report: Primary brain and other central nervous system tumors diagnosed in the United States in 2010-2014. Neuro-Oncology 2017, 19, v1-v88. [CrossRef] [PubMed]

33. Stupp, R.; Mason, W.P.; van den Bent, M.J.; Weller, M.; Fisher, B.; Taphoorn, M.J.; Belanger, K.; Brandes, A.A.; Marosi, C.; Bogdahn, U.; et al. Radiotherapy plus concomitant and adjuvant temozolomide for glioblastoma. N. Engl. J. Med. 2005, 352, 987-996. [CrossRef] [PubMed]

34. Jhanwar-Uniyal, M.; Labagnara, M.; Friedman, M.; Kwasnicki, A.; Murali, R. Glioblastoma: Molecular pathways, stem cells and therapeutic targets. Cancers 2015, 7, 538-555. [CrossRef] [PubMed]

35. Taddei, M.; Donnadio, A.; Costantino, F.; Vivani, R.; Casciola, M. Synthesis, crystal structure, and proton conductivity of one-dimensional, two-dimensional, and three-dimensional zirconium phosphonates based on glyphosate and glyphosine. Inorg. Chem. 2013, 52, 12131-12139. [CrossRef] [PubMed]

36. Suzuki, Y.; Shirai, K.; Oka, K.; Mobaraki, A.; Yoshida, Y.; Noda, S.E.; Okamoto, M.; Suzuki, Y.; Itoh, J.; Itoh, H.; et al. Higher pAkt expression predicts a significant worse prognosis in glioblastomas. J. Radiat. Res. 2010, 51, 343-348. [CrossRef] [PubMed]

37. Li, X.; Wu, C.; Chen, N.; Gu, H.; Yen, A.; Cao, L.; Wang, E.; Wang, L. PI3K/Akt/mTOR signaling pathway and targeted therapy for glioblastoma. Oncotarget 2016, 7, 33440-33450. [CrossRef] [PubMed]

38. Mecca, C.; Giambanco, I.; Bruscoli, S.; Bereshchenko, O.; Fioretti, B.; Riccardi, C.; Donato, R.; Arcuri, C. PP242 Counteracts Glioblastoma Cell Proliferation, Migration, Invasiveness and Stemness Properties by Inhibiting mTORC2/AKT. Front. Cell. Neurosci. 2018, 12, 99. [CrossRef] [PubMed]

39. Ortensi, B.; Setti, M.; Osti, D.; Pelicci, G. Cancer stem cell contribution to glioblastoma invasiveness. Stem Cell Res. Ther. 2013, 4, 18. [CrossRef] [PubMed]

40. Gutkin, A.; Cohen, Z.R.; Peer, D. Harnessing nanomedicine for therapeutic intervention in glioblastoma. Expert Opin. Drug. Deliv. 2016, 13, 1573-1582. [CrossRef] [PubMed] 